\title{
The Human Biological Resource Centres Network
}

\section{A Key Infrastructure for Biomedical Research in Europe}

\author{
Bruno Clément, ${ }_{1}^{1}$ Jean-Alexis Grimaud, ${ }^{2}$ Jean-François Deleuze, ${ }^{3}$ Eric Postaire ${ }^{4}$ and the \\ Participants in Round Table No. 3, Giens XX* \\ 1 INSERM-Transfert, Paris, France \\ 2 Université Paris VI, CNRS UMR N ${ }^{\circ}$ 623, Paris, France \\ 3 Sanofi-Aventis, Evry, France \\ 4 INSERM - Direction de l'Animation et des Partenariats Scientifiques, Paris, France
}

\begin{abstract}
Continuing advances in life sciences and medical research are the result of the remarkable achievements of cell and molecular biology. In the post-sequencing era, the quality of the huge amount of data continuously generated by biotechnology, i.e. genomics, proteomics and high-throughput screening, depends on the quality assurance and the traceability of the original biological materials, including the annotations linked to these materials. Thus, biological resource centres are key infrastructures supporting biotechnology, bioprocessing and the development of new approaches in the prevention, diagnosis and treatment of diseases.

Keywords: biotechnology, biological resources, drugs, diagnosis
\end{abstract}

Changes in the scientific, technological and economic environment have led scientists to establish new collaborative approaches with academic and industrial partners in basic to clinical research. Major breakthroughs from both genome sequencing and large-scale biotechnologies have revealed new approaches that require pre-existing and future partnerships to be redefined, and have placed patients at the heart of the innovative process. In this context, the concept of Human Biological Resource Centres (HBRCs) has recently emerged.

High-throughput technologies generate huge amounts of data, the quality and importance of which depend primarily on the biological materials used, as well as on relevant information linked to these materials. From basic research to drug development, annotated human biological samples and their derivates (e.g. nucleic acids, proteins, antibodies) allow both the identification and validation of therapeutic targets and new drugs, as well as biomarkers crucial in the preclinical and clinical study phases. Quality-assurance procedures used in the process of collection, transformation, storage and access to validated biological resources are becoming a major scientific, economic and ethical issue. The UNESCO (United Nations Educational, Scientific and
Cultural Organisation) international statement on genetics and genomics of October 8, 2003, which followed the 1998 UN statement on the genome, describes the conditions of access to human biological resources, which are based on the universal principles of human rights and dignity as well as the benefits for human beings. ${ }^{[1]}$

\section{Definition}

According to the definition of the OECD (Organisation for Economic Co-operation and Development), ${ }^{[2]}$ Biological Resource Centres (BRCs) are an essential part of the infrastructure underpinning biotechnology. They consist of service providers and repositories of the living cells, genomes of organisms, and information relating to heredity and the functions of biological systems. BRCs contain collections of culturable organisms, e.g. micro-organisms, plant, animal and human cells, replicable parts of these, e.g. genomes, plasmids, viruses, cDNA (complementary deoxyribonucleic acid) banks, viable but not yet culturable organisms, cells and tissues, as well as databases containing molecular, physiological and structural information relevant to these collections, and related bioinformatics.

\footnotetext{
* For a list of participants, please see the end of the article.
} 
According to this general definition, BRC commitments include the following:

- Services dedicated to precise research objectives, as defined by either public or private institutions responsible to the BRC. H-BRCs are either plurithematic, e.g. within a hospital to centralise - totally or partly - the samples generated in the institution, or monothematic, i.e. created for a precise scientific programme, pathology or tissue/organ. If possible, samples are duplicated from one BRC to another in order to guarantee permanent and safe access to materials and attached annotations, e.g. nucleic acids, micro-organisms, cell lines etc.

- Repositories dedicated to samples of special interest, not necessarily related to a specific programme. Collection is justified depending on the quality and scarcity of the human materials and their potential usefulness in the future, e.g. rare DNA, tumours, samples from orphan and neglected diseases.

\section{Objectives}

BRCs make the following possible:

- Storage of human biological resources and their accessibility to R\&D (Research and Development). H-BRCs contain biological materials and relevant information related to both the patient and the sample, with a high level of quality assurance and guaranteed traceability.

- Biotechnology development: high-throughput biological and medical research produces (i) large quantities of data, the validation of which depends on the quality of biological samples and related information; (ii) a wide variety of biological entities required for research progress, including plasmids, micro-organisms, cells, genetically modified animal models, nucleic acids (cDNA, RNA [ribonucleic acid] etc.)

- International exchanges of biological resources according to transparency standards, ethical rules, international treaties and multilateral agreements.

\section{Background}

The identification of pre-existing collections of samples, based on quality assurance and traceability procedures defined by the 'National Committee for Biological Resources', ${ }^{[3]}$ was performed through specific calls launched by both the Ministry of Research and public research agencies. ${ }^{[4]}$

In 2001, INSERM (Institut National de la Santé et de la Recherche Médicale) created an H-BRC committee whose commitments are as follows: to evaluate the projects and the structures; to favour interplay between academic and industrial scientific communities; to create a national and European network; and to contribute to the harmonisation of processes, rules, international recommendations, and standards. Today, the goal is to establish international ISO (International Organisation for Standardisation) standards and to facilitate a bottom-up approach from already recognised H-BRCs.

Recently, a large national body of laws, rules and recommendations has clarified the use of human biological materials for research purposes in relation to patients, bioethics and healthcare policy. ${ }^{[5]}$ These laws define the precise conditions for the collection, storage and access to human biological samples. They represent a unique tool in Europe and constitute a major breakthrough for both academic research and the biotechnology and pharmacological industries.

After an OECD request, France created an international secretary for BRCs. The aim was to create a global BRC network and establish agreement procedures according to international criteria, in order to favour links and exchanges between BRCs and to harmonise international standards and rules.

Access to biological resources with a high level of quality assurance and guaranteed traceability is mandatory for R\&D in the biotechnology and pharmacological industries. Indeed, it is not the description of either DNA sequencing or of gene products that guarantees intellectual property or values, but rather the description and validation of biological functions linked to these genes and their relevance to diseases.

\section{Recommendations}

\subsection{Informed Consent}

Biological samples are obtained during either routine care of patients or within the framework of clinical research. Informed consent of the patient is the basis of the access to samples. A physician must obtain consent after clear and fair information is provided. It must be free, anonymous, and not linked to either gratuities or special advantages. It should be agreed by the patient that the sample will be used within the framework of a scientific programme that can comprise different projects. A possible scientific and commercial valorisation from the data generated by the programme should be mentioned. When the scientific programme produces data of importance for patient care, quality assurance and traceability procedures ensure that relevant information can be conveyed to the patient. Educational and dissemination programmes should be established in close association with charities and patient groups, in order to promote the use of biological samples for the benefit of the patients and society. Accordingly, patient associations and ethical committees should work together to produce clear and fair information and informed 
consent forms. Discussions on the use of human biological samples for the benefit of non-specified scientific programmes, after the original programme is completed, should be initiated.

\subsection{Collection, Storage and Access}

Biological samples are the responsibility of a single institution or organisation, which establishes contracts with other partners when required. The curator's activity should be evaluated $a$ priori and a posteriori. The institution must provide and maintain all the human and financial support necessary for long-term maintenance of the H-BRC. The institution applies to the government authorities within the framework of a single application form. Procedures should be harmonised by ad hoc committees containing members who are specifically qualified in the field of H-BRCs. The maintenance of repositories should be evaluated according to specific procedures and funded according to special rules. Access to samples should be facilitated on the basis of specific agreements defined by contracts and Material Transfer Agreements (MTAs), which establish adapted relationships between the different partners and define the responsibility of each of the partners.

\subsection{Current Actions}

France leads several activities within international organisations, i.e. UNESCO and the OECD, and is empowered to propose specific rules and to harmonise tools dedicated to human biological resources in Europe. At the national level, the definition of standards that could lead to the creation of ISO standards is becoming a priority. The extension of current programmes from both INSERM and the Ministries of Research and Health requires the involvement of all the actors, including national and international agencies, local and regional authorities, and biotechnology and pharmaceutical companies. Several objectives should be completed, including bioinformatics tools, definition of standards and a thesaurus, harmonisation of national rules for exchange, safety, improvement of storage processes, and conditions of access to rare samples in limited amounts, e.g. from rare diseases or tumours. At the European level, France should propose the creation of an H-BRC network, on the basis of a harmonised legal framework focused on specific domains, e.g. cancer and neglected and rare diseases.

\section{Conclusion}

France and Europe are facing a major challenge, i.e. to lead the establishment of a global CRB network. Europe should launch international discussions for the harmonisation of agreements and treaties that might facilitate the exchanges of human biological materials in the near future, on the basis of universal ethical, scientific and economic concepts. It is mandatory to coordinate all the ongoing actions in different European countries, in order to respond to the demands of various partners, particularly from Asia, America and developing countries. The creation of an H-BRC network represents a unique opportunity for France and European countries facing international competition in biomedical research aimed at the discovery of new drugs and diagnostic tools.

\section{Participants}

I. Barilero (Johnson \& Johnson, UK), L. Becquemont (CHU, Le KremlinBicêtre), P.-H. Bertoye (Afssaps, Paris), M.-J. Bonnavita (APHM, Marseille), G. Bricca (Faculté de Médecine, Lyon), B. Clément (INSERM-Transfert, Paris), J.-F. Deleuze (Sanofi-Aventis, Paris), D. Deplanque (Faculté de Médecine, Lille), I. Desbois (EFS, Tours), Y. Deugnier (CIC-CRB, Rennes), J.-H. Di Donato (AFM, Evry), J.-A. Grimaud (Ministère de la Recherche, Paris), J. Haiech (Faculté de Pharmacie, Strasbourg), C. Lassale (LEEM, Paris), J.-M. Laurent-Vo (DGS, Paris), C. Libersa (Faculté de Médecine, Lille), G. Paintaud (CHU, Tours), D. Pinard-Duchamp (DAPS, INSERM, Paris), P.-F. Plouin (HEGP, Paris), E. Postaire (DAPS, INSERM, Paris), S. Ravoire (Lilly, Suresnes), L. Réchaussat (DSI, INSERM, Paris), J.-C. Reynier (APHM, Marseille), P. Vella (Afssaps, Paris).

\section{References}

1. Déclaration internationale sur les données génétiques humaines : conférence générale de l'UNESCO, $322^{\mathrm{mem}}$ session. Paris, 8 octobre 2003 [online]. Available from URL: http://www.unesco.org/confgen/2003/genetic/fr [Accessed 2005 Jul 27]

2. Les centres de ressources biologiques : fondement du développement des sciences de la vie des biotechnologies. Paris: OECD, 2001 [online]. Available from URL: http://www.oecd.org/databasecd/55/48/2487422.pdf [Accessed $2005 \mathrm{Jul} 27$ ]

3. Installation du comité consultatif des ressources biologiques. Discours de M. Roger-Gérard Schwartzenberg, ministre de la Recherche. Paris, le 22 février 2001 [online]. Available from URL: http://www.recherche.gouv.fr/discours/2001/ccrbiod.htm [Accessed 2005 Jun 16]

4. Comité consultatif des ressources biologiques [online]. Available from URL: http://www.crb-france.org [Accessed 2005 Jun 16]

5. Loi ${ }^{\circ} 2002-303$ du 4 mars 2002 relative au droit des malades ; Loi ${ }^{\circ} 2004-800$ du 6 août 2004 relative à la bioéthique ; Loi n ${ }^{\circ} 2004-806$ du 9 août 2004 relative à la politique de santé publique ; Loi n ${ }^{\circ} 2004-801$ du 6 août 2004 relative à la protection des personnes physiques à l'égard des traitements de données à caractère personnel [online]. Available from URL: http://www.legifrance.gouv.fr [Accessed 2005 Jun 16]

Correspondence and offprints: Bruno Clément, Université de Rennes I, Faculté de Médecine et Pharmacie, 2 avenue Léon Bernard, INSERM U-620, Rennes, France.

E-mail: bruno.clement@rennes.inserm.fr 